\section{SESSION 1:}

\section{REGULATION OF DIGESTIVE EVENTS}

\section{Communication no. 1}

Periodic pattern of pancreatic secretory proteins - a call for revision of 'parallel/nonparallel secretory' hypotheses. V. Lesniewska, T. Ploszaj, W. Barej, R. Zabielski (Department of Animal Physiology, Warsaw Agriculture University, Nowoursynowska 166, 02-787 Warsaw, Poland)

A great number of studies on pancreatic secretory responses to food and food components (protein, fat) and neurohormonal secretagogues (e.g. acetylcholine, CCK) have been addressed to solve the problem of parallel versus nonparallel secretion of pancreatic juice proteins. Apparently opposite findings were reported (Liebow, Pancreas 3 (1988) 343-351) possibly due to an ill-defined 'basal' secretion of pancreatic proteins (which was a reference for stimulated secretion). Moreover, since the original studies by Boldyreff on conscious dogs (Boldyreff, Ergebn Physiol. 11 (1911) 121-217) it has been known that in fasting conditions the exocrine pancreas secretes juice in a cyclical pattern that is synchronised with the changes in small intestinal motility. The periodic pattern of pancreatic juice secretion (PPS) associated with the duodenal migrating motor complex (MMC) was later demonstrated in other species including humans (Vantrappen et al., Scand. J. Gastroenterol. 14 (1979) 663-667; DiMagno et al., Dig. Dis. Sci. 24 (1978) 689-693; Zabielski et al., Exp. Physiol. 78 (1993) 675-684; Layer, Pancreas 8 (1993) 181-188). However, a PPS-related vari- ability in the composition of pancreatic juice proteins is still questionable. The aim of this study was to check to what extent the overall composition of pancreatic juice proteins depends on physiological fluctuations in the secretion of pancreatic juice. The present study was performed on five neonatal calves ( 2 weeks old) with chronically implanted duodenal serosal electrodes, pancreatic duct catheter and duodenal cannulas. Sampling of pancreatic juice started 1 week after surgery. Samples of pure, pancreatic juice were collected in the trough at the peak of preprandial PPS/MMC cycles. Duodenal electromyogram (emg) recordings enabled precise identification of MMC phases and their PPS-related cycles. The distribution of secretory proteins in pancreatic juice samples was determined by an SDS-PAGE electrophoresis automated system, scanning and protein band density analysis. In all the examined calves the interdigestive pancreatic secretion fluctuated periodically in phase with the duodenal MMCs. The lowest rate of juice secretion (volume and protein output) was observed during phase I of the duodenal MMC. The juice secretion increased during the early phase II, and the peak was observed during the late phase II of the duodenal MMC. The number of electrophoretically detectable proteins varied according to the phase of the PPS cycle; there were 21 bands detected during the secretory peak (i.e. late phase II of the MMC) and 17 bands were detected during the secretory trough of the PPS (i.e. phase I of the MMC). The number of detectable bands during feeding (cephalic phase) was decreased to 15 bands. Moreover, within the detectable bands there were significant differences in the trace density (band optical density $\times$ band height) between the peak and the trough of the PPS cycle. In conclusion, the present results 
showed that the calf's pancreas during the trough of the PPS cycle did not secrete the same pattern of proteins as during the peak of the PPS cycle or during feeding. The present results clearly show that the overall composition of pancreatic juice proteins is not uniform under physiological conditions during the so-called 'basal' secretion.

\section{Communication no. 2}

The effect of the raw and extruded soybean products on the pancreatic digestive enzyme activities in young calves. M. Kapica, J.L. Valverde Piedra, T. Studzinski (Department of Animal Physiology, Veterinary Faculty, Agricultural University, Akademicka 12, 20-033 Lublin, Poland)

The aim of this study was to determine the influence of raw and extruded soybean meal on the enzyme activities of pancreatic juice in pre-ruminant calves. Twelve calves were fitted 3 weeks after birth with a catheter and a cannula in the pancreatic duct and duodenum, respectively. Experiments lasted for 3 weeks.

Calves were divided into one control group and two experimental groups. All animals were fed a milk diet. Calves from the control group additionally received wheat chaff. Calves from the experimental groups also additionally received, in their liquid fodder, $51.0 \%$ barley, $30.0 \%$ soybean meal and $14.0 \%$ wheat chaff. Animals from the second group received raw soybean meal and animals from the third group received extruded soybean meal. All of the animals were fed liquid food only.

The pancreatic juice outflow increased during the first $15 \mathrm{~min}$ from the beginning of feeding and then decreased between 15 and 45 min of post-feeding time, remained low for $1 \mathrm{~h}$ and increased thereafter until the prefeeding level which was reached about $3 \mathrm{~h}$ after the meal. Total protein content before feeding showed the lowest value $16.08 \pm$ $3.02 \mathrm{mg} \cdot \mathrm{mL}^{-1}$ in the control group, was higher $\left(18.7 \pm 1.8 \mathrm{mg} \cdot \mathrm{mL}^{-1}\right)$ in the third group and was the highest $\left(26.3 \pm 2.06 \mathrm{mg} \cdot \mathrm{mL}^{-1}\right)$ in calves of the second experimental group. Both of the experimental diets increased proteolytic activity of pancreatic juice to $38.83 \mathrm{U} \cdot \mathrm{mg}^{-1}$ of protein and $36.8 \mathrm{U} \cdot \mathrm{mg}^{-1}$ of protein in comparison with the control value in the pre-feeding time $(22.46 \pm$ $1.04 \mathrm{U} \cdot \mathrm{mg}^{-1}$ of protein). The trypsin activity was significantly higher in experimental groups and amounted to $2.97 \pm 0.28 \mathrm{U} \cdot \mathrm{mg}^{-1}$ of protein for calves of the third group and $3.95 \pm 1.86 \mathrm{U} \cdot \mathrm{mg}^{-1}$ of protein for the second group in comparison to the control group $\left(1.84 \pm 0.23 \mathrm{U} \cdot \mathrm{mg}^{-1}\right.$ of protein $)$.

These results demonstrated that the diet containing soybean meal modified the exocrine function of the pancreas mainly by increasing the enzymatic activity of the pancreatic juice.

\section{Communication no. 3}

Influence of histamine administration on pancreatic exocrine secretion in preruminant calves. J.L. Valverde Piedra, M. Kapica, T. Studzinski (Department of Animal Physiology, Faculty of Veterinary Medicine, 20-033 Lublin Agricultural University)

The objective of the present study was to investigate the influence of histamine on pancreatic exocrine secretion in pre-ruminant calves. Experiments were carried out on six calves aged from 6 to 30 days old. The pancreatic juice was continuously collected over 15 min periods. Once the volume of pancreatic juice was measured, a sample was taken for further analyses. The remaining amount was reintroduced into the duodenum using a peristaltic pump. Observations lasted for $3 \mathrm{~h}$ after drug administration. Four different types of experiments were carried out. In the first trial $4 \mathrm{~mL}$ of saline were injected, while in the second trial 36.36 $\mu \mathrm{g} \cdot \mathrm{kg}^{-1}$ b.w. of histamine were injected, in the third trial $36.36 \mu \mathrm{g} \cdot \mathrm{kg}^{-1}$ b.w. of histamine 